Table 1. Characteristics of the AOSD patient

\begin{tabular}{|c|c|c|c|c|c|c|c|c|c|c|}
\hline No. & Sex & $\begin{array}{l}\text { Age } \\
\text { (year) }\end{array}$ & Main symptoms & Treatments before JAKi onset & JAK inhibitors & $\begin{array}{l}\text { Steroids at } \\
\text { onset }(\mathrm{mg} / \\
\text { day) }\end{array}$ & $\begin{array}{c}\text { Concomitant } \\
\text { treatment }\end{array}$ & $\begin{array}{l}\text { Response at } \\
\text { last F-U }\end{array}$ & $\begin{array}{l}\text { Steroids at } \\
\text { the end of F-U } \\
\text { (mg/day) }\end{array}$ & $\begin{array}{c}\text { F-U } \\
\text { (months) }\end{array}$ \\
\hline 1 & $\mathrm{~F}$ & 6 & Fever, polyarthritis, rash & $\begin{array}{c}\text { AINS, ANAKI, TOCI, CANAKI, } \\
\text { ADA, THALI, INFLIX }\end{array}$ & RUXOLITINIB 5mgx2/day & 3 & 0 & $\mathrm{P}$ & 1 & 23 \\
\hline 2 & $\mathrm{M}$ & 28 & Fever, polyarthritis, rash & ANAKI & BARICITINIB 4mg/day & 80 & 0 & $\mathbf{N}$ & 10 & 1 \\
\hline 3 & M & 32 & Fever, polyarthritis, rash & $\begin{array}{c}\text { TOCI+MTX, ANAKI+MTX, } \\
\text { CANAKI+MTX, ADA, CICLO, } \\
\text { IgIV }\end{array}$ & BARICITINIB 4mg/day & 16 & $\begin{array}{c}\text { MTX } 20 \mathrm{mg} / \text { week } \\
\text { ANAKINRA } \\
\text { 100mg/day }\end{array}$ & $\mathrm{P}$ & 12 & 19 \\
\hline 4 & $\mathrm{~F}$ & 40 & Fever, polyarthritis, rash & $\begin{array}{c}\text { MTX, IMUREL, CICLO, } \\
\text { ETANERCEPT, ANAKI+MTX, } \\
\text { TOCI+MTX, IgIV }\end{array}$ & $\begin{array}{l}\text { RUXOLITINIB 15mgx2/ } \\
\text { day }\end{array}$ & 60 & ANAKI $200 \mathrm{mg} /$ day & $\mathrm{P}$ & 30 & 4 \\
\hline 5 & $\mathrm{~F}$ & 48 & Fever, polyarthritis, rash & $\begin{array}{l}\text { TOCI, ANAKI, CICLO, CANAKI, } \\
\text { IMUREL }\end{array}$ & TOFACITINIB 5mgx2/day & 50 & 0 & $\mathrm{P}$ & 7.5 & 9 \\
\hline 6 & $\mathrm{~F}$ & 50 & Fever, polyarthralgia, rash & ANAKI & BARICITINIB 4mg/day & 60 & 0 & $\mathbf{N}$ & 40 & 1 \\
\hline
\end{tabular}

F-U: Follow-upN: No responseP: Partial response

or baricitinib) and failure in 2 (33.3\%) (patients with baricitinib). No patient achieved complete remission. At the last visit, steroids could be decreased but not stopped in all patients. Patients with partial response had an average decrease of $72,8 \%$ ( $90 \%$ for tofacitinib, $70 \%$ for baricitinib, $58.5 \%$ for ruxolitinib between the start and the follow-up end date) and non-responder patients were yet able to reduce steroids by $60,5 \%$ (Table 1). Tolerance of JAK inhibitors was excellent, however patient 4 experienced an episode of infectious pulmonary disease.

Conclusion: JAK inhibitors therapy may be helpful for some patients with refractory Still's disease. However, no complete response was observed in this short series of cases. There might be a difference of response between the molecules, although the number of patients is too low to draw conclusions. Additional information is thus needed to evaluate more precisely the risk-benefit ratio of this treatment, and a possible difference in efficacy among the different groups of JAK inhibitors.

REFERENCES:

[1] Hu Q, Wang M, Jia J, et al. Ann Rheum Dis 2020;0:1-3. doi:10.1136/ annrheumdis-2019-216
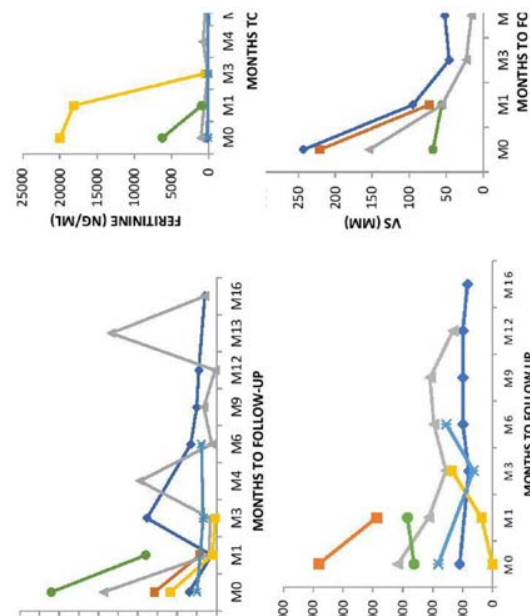

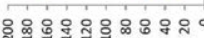
$(1 / 9 w)$ d
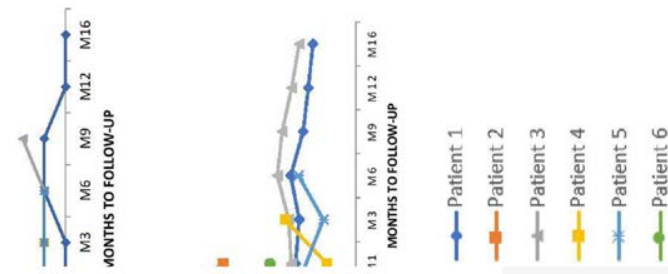

Acknowledgements: I thank all the coauthors, particularly Stéphane Mitrovic and Bruno Fautrel. Also, a special thank to the CRI.
Disclosure of Interests: None declared

DOI: 10.1136/annrheumdis-2021-eular.2210

\section{AB0773 1 PATTERN OF MACROPHAGE ACTIVATION SYNDROME IN RHEUMATIC DISEASES}

R. Maheshwari ${ }^{1}$, R. Sankaralingam2, R. R2, S. Chinnadurai2, B. Chilukuri2, M. Mani2, J. Antony2. ${ }^{1}$ Sri Ramachandra Institute of Higher Education and Research, Clinical Immunology and

Rheumatology, Chennai, India; ${ }^{1}$ Sri Ramachandra Institute of Higher

Education and Research, Clinical Immunology and Rheumatology,

Chennai, India

Background: Macrophage activation syndrome (MAS) is a rare, potentially fatal condition complicating autoimmune diseases, as their initial manifestation or during its course.

Objectives: To describe the pattern of MAS and its salient features in patients with rheumatic diseases.

Methods: A retrospective observational study was conducted in 16 patients diagnosed with MAS, due to rheumatic diseases in Department of Rheumatology, SRIHER, Chennai from January 2018-December 2020.

Results: The primary diseases were Systemic Lupus Erythematosus(SLE) in $75 \%(n=12)$,Adult Onset Still Disease(AOSD) in $18.7 \%(n=3)$ and Kikuch Disease in $6.25 \%(n=1) .50 \%(n=8)$ presented with MAS as the initial manifestation.Others had a known rheumatic disease with an average duration of 6.5 years. Occult MAS was seen in $25 \%(n=4)$. The most frequent clinical features were unremitting fever $(n=15)$ and splenomegaly $(n=15)$. All had hyperferritinemia-mean of $2971.10 \mathrm{ng} / \mathrm{mL}(531-12536)$.Sub group analysis showed significant hypofibrinogenemia(129.8 vs $200.62 \mathrm{mg} / \mathrm{dl})$ in patients presenting with MAS as their initial manifestation. Transaminitis(666/252.5 vs $243 / 217.62 \mathrm{U} / \mathrm{L}$ ), hypertriglyceridemia(316 vs $275.8 \mathrm{mg} / \mathrm{dl})$, high $\mathrm{LDH}(2490$ vs 938.75) were more severe in this group, but not significant.All with SLE had increased disease activity, with $50 \%(n=8)$ having SLEDAI $2 K$ of $\geq 15$. Bone marrow aspiration showed haemophagocytes in $81.25 \%(n=13) . \mathrm{H}$ score of $>169$ was seen in $93.75 \%(n=15)$. Infection was the commonest trigger for $\operatorname{MAS}(n=9)$-bacterial $(n=5)$, viral $(n=4)$, fungal $(n=1)$ and mycobacterial $(n=2)$, followed by parturition $(n=1)$. All patients were managed with pulse steroids followed by intravenous cyclophosphamide $(n=8)$, rituximab $(n=2)$, mycophenolate mofetil $(n=2)$ in SLE, tocilizumab $(n=2)$ and etoposide $(n=1)$ in AOSD. Mortality rate was $18.75 \%(n=3)$.

Conclusion: Spectrum of MAS in rheumatic diseases could be occult, associated with infection,high disease activity,or lead to mortality. High index of clinical suspicion is required, due to overlap of features like fever, cytopenias and organomegaly in MAS \& SLE.Hyperferritinemia, high LDH, \& transaminitis could aid in differentiating \& early diagnosis. New criteria for rheumatic diseases,including these parameters are needed, especially in resource-limited settings where sIL$2 \mathrm{R} \alpha$ \& NK cell activity tests are not feasible.

\section{REFERENCES:}

[1] Stuart J.Carter et al. Macrophage activation syndrome in adults:Recent advances in pathophysiology, diagnosis and treatment. Rheumatology 2019;58;5-17

[2] Ai-Chun Liu et al.Macrophage activation syndrome in systemic lupus erythematosus:a multicentre,case-control study in China.Clin Rheumato 2017. 
Table 1. MAS-SALIENT FEATURES

\begin{tabular}{|c|c|c|c|}
\hline FEATURES & $\begin{array}{l}\text { INITIAL MANIFESTATIONS } \\
{[\mathrm{n}=8]}\end{array}$ & $\begin{array}{l}\text { KNOWN RHEUMATIC } \\
\text { DISEASES[n=8] }\end{array}$ & $\begin{array}{c}P \\
\text { VALUE } \\
(<0.05)\end{array}$ \\
\hline \multicolumn{4}{|c|}{ Primary rheumatic diseases } \\
\hline SLE & $5(62.5 \%)$ & $7(87.5 \%)$ & - \\
\hline AOSD & $2(25 \%)$ & $1(12.5 \%)$ & \\
\hline Kikuchi disease & $1(12.5 \%)$ & 0 & \\
\hline Fever & $8(100 \%)$ & $7(87.5 \%)$ & 0.30 \\
\hline Respiratory & $2(25 \%)$ & $5(62.5 \%)$ & 0.13 \\
\hline Neurological & $1(12.5 \%)$ & $4(50 \%)$ & 0.10 \\
\hline Bleeding & $2(25 \%)$ & $1(12.5 \%)$ & 0.52 \\
\hline Splenomegaly & $8(100 \%)$ & $7(87.5 \%)$ & 0.30 \\
\hline Hepatomegaly & $6(75 \%)$ & $3(37.5 \%)$ & 0.13 \\
\hline Haemoglobin(g/dl) & 8.58(5.4-11.7) & $8.2(5.2-11.5)$ & 0.70 \\
\hline WBC $\operatorname{count}(/ \mu \mathrm{L})$ & $5550(1000-11800)$ & $3477.5(1200-6200)$ & 0.19 \\
\hline Platelet count $\left(\times 10^{9} / \mathrm{l}\right)$ & $1.41(0.30-2.4)$ & $1.35(0.32-1.8)$ & 0.90 \\
\hline $\operatorname{ESR}(\mathrm{mm} / \mathrm{hr})$ & $76.75(42-137)$ & $68(20-127)$ & 0.65 \\
\hline AST(U/L) & $666(36-3481)$ & $257.75(45-642)$ & 0.36 \\
\hline $\operatorname{ALT}(\mathrm{U} / \mathrm{L})$ & 252.5(18-790) & 217.62(28-1044) & 0.82 \\
\hline LDH(U/L) & $2490.12(164-16,000)$ & $938.75(357-1569)$ & 0.44 \\
\hline Ferritin(ng/ml) & 2187.46(532-7500) & $3754.75(531-12536)$ & 0.37 \\
\hline Triglycerides(mg/dl) & $316(53-551)$ & 275.8(160-317) & 0.52 \\
\hline Fibrinogen(mg/dl) & $129.8(76-178)$ & $200.62(140-292)$ & 0.009 \\
\hline Complement 3(mg/dl) & $39.14(13-60)[n=5]$ & $57.72(32-95)[n=7]$ & 0.16 \\
\hline Complement 4(mg/dl) & $4.24(1.2-6)[n=5]$ & $14.22(2.8-34)[\mathrm{n}=7]$ & 0.07 \\
\hline $\begin{array}{l}\text { Anti dsDNA antibod- } \\
\text { ies[ELISA] IU/ml }\end{array}$ & $596.2(90-1151)[n=5]$ & $316.82(10-800)[n=7]$ & 0.26 \\
\hline
\end{tabular}

MAS-Macrophage activation syndrome,WBC-white blood cell,ESR-erythrocyte sedimentation rate,AST-aspartate aminotransferase, ALT-alanine aminotransferase, LDH-lactate dehydrogenase, dsDNA-double standed deoxyribonucleic acid

Disclosure of Interests: None declared

DOI: 10.1136/annrheumdis-2021-eular.2965

\section{AB0774 SCHNITZLER'S SYNDROME: A 5-YEAR CLINICAL EXPERIENCE}

S. Salugina ${ }^{1}$, V. Gorodetskiy ${ }^{2}$, E. Fedorov ${ }^{1}$, V. Rameev ${ }^{3}$, E. Borzova ${ }^{4,5}$, N. Lopatina ${ }^{6} .{ }^{1}$ V.A.Nasonova Research Institute of Rheumatology, Pediatric Department, Moscow, Russian Federation; ${ }^{2}$ V.A.Nasonova Research Institute of Rheumatology, Laboratory of Intensive Therapy Methods, Moscow, Russian Federation; ${ }^{3}$ Sechenov's First Moscow State Medical University, E. M. Tareev Clinic of Rheumatology, Neurology and Occupational Pathology, Moscow, Russian Federation; ${ }^{4}$ Sechenov's First Moscow State Medical University, Department of Dermatology and Venereology, Moscow, Russian Federation; ${ }^{5}$ Research and Clinical Institute of Pediatrics n.a. Yuri Veltischev, Department of Clinical Genetics, Moscow, Russian Federation; ${ }^{6}$ V.A. Nasonova Research Institute of Rheumatology, 5th Rheumatology Department with Hematology Beds, Moscow, Russian Federation

Background: Schnitzler's syndrome (SchS) is a rare non-monogenic auto-inflammatory disease (AID) which manifests in adults and is characterized by recurrent urticarial lesions, monoclonal gammopathy, and other manifestations of a systemic inflammatory response (fever, muscle / joint / bone pains, leukocytosis, increased ESR, CRP). Off-label treatment with IL-1 inhibitors (anakinra, canakinumab) was shown to be highly effective and well tolerated in pts with SchS based on a few multicenter studies and practical experience.

Objectives: To analyze a real-life experience of the treatment with IL- 1 inhibitors in pts with SchS in the rheumatology tertiary care settings.

Methods: The study included 7 pts ( 3 women, 4 men) with treated with IL-1 inhibitors (anakinra, canakinumab). A median age at the diagnosis was 44 years old ( 25 -68). Age at the disease onset ranged from 22 to 66 . All pts met the Strasbourg diagnostic criteria. 7 pts received canakinumab, while 3 pts were first treated with anakinra followed by a switch to canakinumab. Anakinra was administered subcutaneously $100 \mathrm{mg}$ per day. Canakinumab was given subcutaneously at a dosage of $150 \mathrm{mg}$ every 8 weeks. The treatment duration with anakinra ranged from 1 week to 2.5 months with further switching to canakinumab. The duration of canakinumab treatment by the time of analysis ranged from 2 months to 5.5 years. Results: All pts at the inclusion into the study suffered from urticarial rash, pains in bones and joints, fatigue, fever (6), increased acute phase marker levels (ESR, CRP), monoclonal gammopathy, mainly lgMk (4.7 - 9g/l). An average period between the disease onset and the treatment initiation was 3 years (2 to 4). In all pts lymphoproliferative diseases and monogenic AIDs (CAPS, TRAPS) were excluded. Before the treatment with IL-1 inhibitors, all pts had received NSAIDs and/or GCs, methotrexate - 2, plaquenil-2. During the treatment with IL-1 inhibitors, 6 out of 7 pts had a complete response as demonstrated by a symptom resolution within several days and a rapid decrease in ESR and CRP levels. In 3 pts, who responded anakinra, the treatment was switched to canakinumab. In one patient with a partial response to anakinra, there was a loss of the effect upon switching to canakinumab, In one patient, the interval between canakinumab injections was increased up to 5 months without a symptom relapse. This patient fathered a healthy child whilst on treatment with canakinumab. The therapy was well tolerated in all pts, no SAE were noted.

Table 1. Clinical and demographic characteristics of patients with SchS

\begin{tabular}{lccccccc}
\hline Patients & 1 & 2 & 3 & 4 & 5 & 6 & 7 \\
\hline Sex & $\mathrm{M}$ & $\mathrm{F}$ & $\mathrm{M}$ & $\mathrm{F}$ & $\mathrm{F}$ & $\mathrm{M}$ & $\mathrm{M}$ \\
\hline Age $(\mathrm{y})$ & 44 & 32 & 56 & 68 & 25 & 51 & 49 \\
Age of disease onset $(\mathrm{y})$ & 40 & 29 & 53 & 66 & 22 & 39 & 47 \\
Urticarial rash & + & + & + & + & + & + & + \\
Fever & + & - & + & + & + & + & + \\
Fatigue & + & + & + & + & + & + & + \\
Bone pain & + & + & + & + & + & + & + \\
Arthralgia/arthritis & + & + & + & + & + & + & + \\
ESR(normal $<15 \mathrm{~mm} / \mathrm{h})$ & 31 & 140 & 100 & 49 & 81 & 53 & 56 \\
CRP (normal $<5 \mathrm{mg} /$ /) & 107 & 44 & 192 & 96 & 369 & 76 & 41,82 \\
IgM kappa $(\mathrm{g} / \mathrm{l})$ & $7,1-5,2$ & $4,7-7,8$ & 7,6 & - & - & 5,2 & 9 \\
IgM lambda(g/l) & - & - & 1,36 & - & - & - & - \\
IgG kappa $(\mathrm{g} / \mathrm{l})$ & - & - & - & 5,1 & - & - & - \\
IgG lambda $(\mathrm{g} / \mathrm{l})$ & - & - & - & - & 10,7 & - & - \\
\hline
\end{tabular}

Conclusion: SchS is a rare disease that occurs in the practice of a rheumatologist. Short and long acting IL-1 inhibitors are highly efficient and safe treatment options for pts with SchS. A switching from short to long acting IL-1 inhibitors can be effective in SchS pts.

\section{REFERENCES:}

[1] Krause K, Tsianakas A, Wagner N, Fischer J, Weller K, Metz M, et al. Efficacy and safety of canakinumab in Schnitzler syndrome: a multicenter randomized placebo-controlled study. J Allergy Clin Immunol 2017;139:1311-20.

[2] Betrains A., Staelsa F, Vanderschueren S. Efficacy and safety of canakinumab treatment in schnitzler syndrome: A systematic literature review Seminars in Arthritis and Rheumatism 50 (2020) 636-642.

Disclosure of Interests: None declared

DOI: 10.1136/annrheumdis-2021-eular.3176

\section{AB0775 MANY RARE AND SERIOUS LOCALIZATIONS IN ONE CASE WITH HEREDITARY EXOSTOSES}

R. Sarraj ${ }^{1}$, M. Ghali', R. Ben Chehida ${ }^{1}$, G. Mouna ${ }^{1}$, I. Bejia ${ }^{1}$, J. Mahbouba ${ }^{1}$, S. Zrour ${ }^{1}$, M. Touzi' ${ }^{1}$ N. Bergaoui'. ${ }^{1}$ Fattouma Bourguiba Hospital, Rheumatology, Monastir, Tunisia

Background: Multiple hereditary exostoses (MHE) is an inherited disorder of bone growth. People who have MHE grow exostoses or boney bumps on their bones that vary in size, location and number. Some localizations are rare but potentially serious such as ribs, spine or pelvis due to proximity to importan structures.

Objectives: The aim of this case report was to illustrate the clinical and radiographic features of some rare localizations of MHE.

Methods: We are reporting a rare case of a thirty one-year-old male with severe localizations of MHE.

Results: A thirty one-year-old male affected by hereditary multiple exostoses., no followed up, came to our consultation complaining about chest pain. On examination, he walks with a limp because of the unequalness of his limbs. The osteoarticular examination revealed numerous palpable osseous masses at the distal and proximal end of the 2 arms, 2 forearms, 2 thighs and 2 legs and the right iliac wing. Neurological examination revealed vivid deep tendon reflexes, bilateral positive Hoffmann'sign and Babinski reflex associated with right hemiparesis. The pulmonary exam was normal. Medullary MRI showed medullary compression with spinal cord atrophy and sign of myelopathy of c1 c2 segment. The ct-scan revealed multiple exostosis, the two largest lesions were located in the second rib measuring $45 \mathrm{~mm} * 35 \mathrm{~mm}$ axially and $52 \mathrm{~mm}$ in height compromising blood vessels, and in the right iliac bone with a retroperitoneal growing mass measuring 126 * $94 \mathrm{~mm}$ axially and $100 \mathrm{~mm}$ in height leading to a serious entrapment of the axial skeleton and the abdominal organs. It also confirmed thickening of the cartilage cap of the right iliac bone suggestive of malignant chondrosarcomatous transformation.

Conclusion: Exostoses are the most common benign bone tumors. Its complications are rare but can cause a functional disability or even a vital risk.

\section{REFERENCES:}

[1] Eke GK, Omunakwe HE, Echem RC. Hereditary multiple exostoses in a 15-year-old boy: A case report and review of literature. Niger J Paediatr. 2016;43(4):295.

Disclosure of Interests: None declared

DOI: 10.1136/annrheumdis-2021-eular.3296 